\title{
An Assessment of the Applicability of Behavioral Economics' Tools to Policy Making Process Considering Sustainable Development Goals
}

\author{
Abeer Mohamed Ali Abd Elkhalek ${ }^{1}$ \\ ${ }^{1}$ College of Management and Technology, Arab Academy for Science, Technology and Maritime Transport, \\ Egypt \\ Correspondence: Abeer Mohamed Ali Abd Elkhalek, College of Management and Technology, Arab Academy \\ for Science, Technology and Maritime Transport, Egypt. E-mail: abeer_abdelkhalek@yahoo.com
}

Received: July 30, 2020

Accepted: August 25, 2020

Online Published: September 15, 2020

doi:10.5539/ijef.v12n10p57

URL: https://doi.org/10.5539/ijef.v12n10p57

\begin{abstract}
Achieving sustainable development goals in a very dynamic and complicated world requires innovated solutions. As people are in the heart of the developmental process, understanding what motivates people and what drives their behaviors is a must for designing policies targeting the achievement of developmental goals. This paper aims to assess how the behavioral economics' tools may be applied to directing people's behaviors toward more sustainable activities and then contributing to achieve sustainable development goals. Using deductive qualitative approach, and a comparative analysis, the study explores and discusses to what extent insights and techniques from behavioral economics may affect and change policy making process and then public policies' outcomes specifically in the context of sustainable development disciplines. The results showed a vital role of behavioral economics tools in developing public policies in accordance to real behavior of people which -in turnhelp in achieving sustainable development goals. Moreover, it was concluded that changing humans' behavior toward more sustainable patterns of life provides so many opportunities to strengthen the effectiveness of policies for sustainable development in both developed and developing countries. Using behavioral economics tools, policymakers can design more effective policies to achieve Sustainable Development Goals (SDGs).
\end{abstract}

Keywords: Behavioral Economics (BE), Behavior Insights (BI), Behavioral Economics Team (BET), Sustainable Development Goals (SDGs)

\section{Introduction}

Most of development economics research focuses on alleviating poverty and enhancing more justice in income distribution. Sustainability can be enhancement only if alleviating poverty and reducing income inequality -taking into account environmental considerations- are integrated with sustainable patterns of behavior in the society. Sustainable development is the continuous procedures that policy makers use to fulfil the needs and requirements of the present generations without compromising the ability of future generations to meet their own needs (Brundtland, 1987; Stephen et al., 2019). Sustainable development process must make an accurate balance between the present and the future to ensure that all generations will live in a good environment and have a better standard of live considering the available resources. The challenge faced by policy makers in that context is to answer the questions: How to maintain the targeted balance between the different dimensions of 
developmental process, and How to make ensure that the futural generations will get their rights in the resources and environment?

A part of the answer may be that human behavior in the consumption and production domains is a key factor affecting the governments' efforts to allocate resources between the present and the future to enhance justice between the different generations regarding the complicated relationship between the various dimensions of sustainable development and the various goals of every dimension. Then, policy makers must understand and integrate the psychological and behavioral factors of individuals when designing and implementing policies targeting developmental goals to increase the efficiency and effectiveness of those policies in achieving its targets. It can be done by employing behavioral economics tools in the policy making process.

Behavioral economics studies and analyses the psychological and social factors which influence the behavior of people and organizations. The key idea here that behavioral insights indicate that human behavior is not always economically rational as assumed in neoclassical economics Theories, and the individuals' decisions are- to some extent- Influenced by psychological factors and social circumstances (Dirk \& Julia, 2018).

In 2015, United Nations approved 17 Sustainable Development Goals to promotes economic development with its social and environmental dimensions which is so called "the Millennium Sustainable Development goals" including poverty alleviation, improving standards of living and maintaining better allocation of natural capital necessary for future development. (Stephen et al., 2019). So, there is an urgent need for policy makers to consider the interrelation between the economic, social, and environmental dimensions of sustainable development when targeting the achievement of its goals.

Behavioral economics shows that in the real live, individuals are influenced by mental biases that enforce them to act irrationally. (Sent, 2004; and Heukelom, 2014) proved that decision making process is mostly interrupted and moving a way from what the traditional theory of economics assumes.

This paper discusses some key behavioral insights that help to explain the challenges and opportunities of modifying human behavior's patterns toward sustainability and describes several effective examples of how behaviorally informed policies have been implemented in both developing and developed countries. This study also introduces important recommendations related to the mechanisms of shifting behavior in desirable directions and designing policies to achieve desirable outcomes by integrating economics with other disciplines in pursuit of sustainable development which includes three dimensions: economic, social and environmental dimension, A society cannot be sustainable unless it has incorporated social justice, economic welfare, as well as environmental protection, into its guiding principles (Fawad, 2019).

\section{Material and Methods}

To achieve the main objective of this study, the methodology used is descriptive in nature because it mostly explores the applicability of BE tools to policy making process regarding each dimension of sustainable development (economic, social and environmental dimensions) considering countries' experiences. The empirical study depends on a combination of inductive and deductive approach to draw a complete picture about how policy makers can use BI and BE tools to improve and innovate new effective policies to achieve SDGs. This study analyses the existing evidence regarding the role, restrictions and the changing degree of success of $\mathrm{BE}$ tools in designing public policies.

\section{Results}

\subsection{BE Tools and Economic Dimension of Sustainable Development}


Sustainable development process must include appropriate mechanisms of allocating the available resources to make the balance between present and future generations' needs. Focusing on SDGs, specifically goal 1 (End poverty) and goal 12 (Ensure sustainable consumption and production patterns), data collected showed that: (UNDP, 2020)

- $10 \%$ of world's population live in extreme poverty.

- 1.3 billion people live in multidimensional poverty.

- 1.3 billion tonnes of food are wasted every year, while almost 2 billion people go hungry or undernourished.

- The food sector accounts for around $22 \%$ of total greenhouse gas emissions, largely from the conversion of forests into farmland.

- Only $3 \%$ of the world's water is clean, and humans are using it faster than nature can replenish it.

- $\quad 20 \%$ of the world's final energy consumption in 2013 was from renewable sources.

Sustainable consumption and production have a key role to play related to increasing resource effectiveness, encouraging sustainable lifestyles, and alleviate poverty rates (Saugato \& Sendhil, 2014).

policymakers must consider that moving toward more sustainable patterns of consumption and production is essential to achieve developmental goals. In that context, the small decisions that individuals daily make have significant effects on the developmental process which shed the light on the importance of changing human behavior towards more sustainable choices (UNEP, 2017).

Policymakers have various tools to affect and modify behavior, such as regulations, prices, and incentives, but first they need to understand the determinants of that behavior, or they will meet more challenges related to the limited returns of their policies.

Employing findings from behavior economics, which draws on main improvements in the study of decision-making to better understand the complications of personal behavior, in designing public was proved in many countries as an affective mechanism to modify consumer choice and increase developmental returns.

Evidence from behavioral and experimental economics suggests that people care about the welfare of others (Charness \& Rabin, 2002), they are affected by their short-term feelings (Loewenstein \& Lerner, 2003), and they resort to heuristics when faced with a complex choice environment among others (Gabaix et al., 2006). Behavioral economists proposed to nudge and wink people to make better choices for them and the society around the globe. Behavioral economics concentrates less on organizations, especially markets and their disappointments, but on failures in decision making. Policy is therefore less disposed to regulate the market, but rather the behavior of individuals on markets. The application of behavioral economics to business sector economic analysis is a cutting-edge method to secure the power of real-world related economics (Dirk \& Julia, 2018).

Behaviourally informed policy tools can help individuals better assess costs and benefits and act on their preferences, improving the efficiency of government interventions. The behavioral perspective on decision making indicates that apparently small and low-cost policy. Changes in behaviours may also have a huge effect on the accomplishment of development targets concerning the reduction of poverty. Using many policy tools, policy makers can help people make better decisions, which in turn reduce poverty. Those tools include framing, anchoring, simplification, reminders, and commitment devices. The evidence shows that while policy makers 
may not be able to solve individuals' behavioral restrictions, a psychologically informed understanding of decision making can help them to recognize those constraints and design policy to account for them and improve the match between intended and actual effects of public policies. For instance, behavioral economics has provided new answers and new approaches to important questions in many areas of economics such as the questions about why the poor stay poor (Banerjee \& Mullainathan, 2008). It has furthered our understanding of the nature of poverty by showing how poverty is as much about psychological and cognitive scarcity as about financial and material deprivation, which are the focus of traditional economic theorizing about poverty (Bertrand et al., 2004)

\subsection{BE Tools and Social Dimension of Sustainable Development}

Improving the economic, social, and environmental well-being requires making substantial changes in social policy regulation and economic improvements. Thus, psychology can also be applicable to sustainable development by helping to shape social policies that foster mental health and well-being in both developed and developing countries. Focusing on SDGs, specifically ending hunger and improving nutrition (goal 2) and achieving gender equality (goal 6), the available data showed that: (UNDP, 2017)

- The number of hungry persons is about 821 million in 2017, 63\% out of them are in Asia.

- $\quad$ About 151 million children under five, 22\%, are stunted.

- More than 1 in 8 adults is overweight.

- 1 in 3 women of work force have diseases related to shortage in the haemoglobin percentage in the blood as a global average.

- $\quad 750.000 .000$ girls were married before the legal age of marriage (18 years old).

- In many countries, husbands can legally prevent their wives from working; in 39 countries, daughters and sons do not have equal inheritance rights; and 49 countries lack laws protecting women from domestic violence.

- $20 \%$ of women have suffered from physical and/or sexual violence by an intimate partner within the last year, and 49 countries have no laws that protect women from such violence.

- Females represent only $13 \%$ of agricultural land holders.

- Women in Northern Africa countries get no more than $20 \%$ rewarded jobs in sectors rather than agricultural sector. The percentage of females in paid employment outside the agriculture sector represent only $41 \%$ in 2015.

Empirical evidence proved that changing human's behavior and society's norms is a must for achieving social sustainability. For example, it was proved that the large gender gap in educational fulfilment between young females and males in India is in part due to the belief that there are limited monetary returns from educating females, whose main social role is thought to be restricted to housework. That opinion is confusing as they encourage pulling girls out of school, which in turn means that their economic chances in fact stay restricted. To solve this problem, Jensen (2012), founded that affording villagers a accurate data about the jobs opportunities available for women with high-school degrees may encourage them to continue learning for a longer years and delay marriage to benefit from the hight salaries they can obtain from the available jobs. Another way in which psychology and social norms is relevant is the application of their insights and tools to deal with the undesirable behavior which has negative impacts on economic development and specifically, sustainable development in 
forms of disaster relief, environmental pollution, and irrational use of resources. Psychological insights may help here as indicators of unsustainable development and can provide policy makers and professionals various tools to manage undesirable behavior and shift it toward more sustainable practises (Fawad, 2019)

Revealing the possibility of behavioral solutions needs to take a systematic approach to classifying essential difficulties, assessing the possible influence of behavioral economics methods, and interpreting these perceptions into developments in programs. This can only be attained by making some deep-seated changes in the way we go about applying behavioral insights in development. This requires that governments must integrate behavioral insights in the process of designing developmental programs and to experimenting on existing programs.

\subsection{BE Tools and Environmental Dimension of Sustainable Development}

The environmental sciences have recorded large and annoying changes in planet systems, from climate change and loss of biodiversity, to changes in hydrological and nutrient cycles and exhaustion of natural resources. These undesirable changes in the environmental components have great harmful impacts on future human life and generate worries about whether the countries all over the world are on the right way to sustainable development or on the wrong and move a way from achieving sustainable development goals (Sergey et al., 2014). Hence, achieving economic development considering the environmental considerations require making a balance between economic performance, social wellbeing, and environmental protection along with the insurance of justice between the present and future generations a necessity for the continuation of life on the earth. It could be achieved through an understanding the interactions between the different dimensions of sustainable development (Shohel \& Howes, 2011).

Focusing on SDGs, specifically goal 7 (Ensure access to affordable, reliable, sustainable and modern energy) and goal 13 (Take urgent action to combat climate change and its impacts), available data showed that: (UNDP \& IPCC, 2019):

- Energy is the major supplier to climate change as it produces more than $60 \%$ of greenhouse gases.

- $\quad$ One in 7 people still lacks electricity, and most of them live in rural areas of the developing world.

- More efficient energy standards could reduce building and industry electricity consumption by $14 \%$.

- About $40 \%$ of the world's population depend on polluting and unhealthy fuels for cooking.

- $\quad 20 \%$ of power was produced through renewable sources.

- To restrict warming to $1.5 \mathrm{C}$, global net $\mathrm{CO} 2$ emissions must decrease by $45 \%$ between 2010 and 2030 and reach net zero around 2050 .

- Climate pledges under The Paris Agreement cover only one third of the emissions reductions needed to keep the world below $2^{\circ} \mathrm{C}$.

- Global emissions of carbon dioxide have increased by almost 50 per cent since 1990.

- Global emissions of carbon dioxide have increased by almost 50 per cent since 1990

- Emissions grew more quickly between 2000 and 2010 than in each of the three previous decades.

Balancing between economic growth and environmental considerations is more than challenging, but it is still possible through innovating new technologies, integrating climate change measures into national policies, strategies and planning, In addition, it could be done by targeting some changes in behaviours toward more sustainable patterns of consumption, production, and other aspects of life. For example, Norway has an 
independent organisation promoting and supporting the use of behavior insights in designing environmental policies. That organisation- called "GreeNudge"- has an obvious emphasis on sustainability and aims to initiate, fund and encourage research into behavioural change to alleviate climate change.

The three most environmentally relevant areas of consumption, which together sum up to $75-80 \%$ of the life cycle environmental impacts in industrialised countries are housing (especially heating systems), transport (especially car use and air travel) and food and drink (especially meat and dairy) (EEA, 2013). These areas are also the ones where nudge researchers and practitioners see the largest potential (Stordalen \& Kallbekken, 2014).

The households' consumption patterns of energy mostly show that behavior is not economically rational. One of the important contributions of behavioural economics to energy efficiency policy is to counteract the economics-based reasoning, which argues that there cannot be an "energy efficiency gap" since people always behave rationally (Geller \& Attali, 2005; Gillingham \& Palmer, 2014).

In a study of the impact of an eight-month period of obligatory electricity saving in Brazil, evidence indicates that the policy led to a continued decrease in electricity use, with consumption $14 \$ \%$ lower even 10 years after rationing ended. Household data on the ownership of appliances and on consumption habits indicate that a change in habits was the main reason for the decrease in consumption (Costa, 2012).

Another example comes from "O power", a leading US provider of customer engagement and energy efficiency cloud services to utilities (Allcott, 2011).

Hence, it would be best not to apply behavioral economics and behavioral insights as a separate policy area, but as an integrating and cross-cutting design element in policy making process. For instance, policy makers could work to include "green defaults" and require that applications be designed to enable and prompt sustainable behavior. If they were offered as defaults, users who do not want these features can then change them, but systems must be designed for sustainable behavior.

\section{Discussion}

\subsection{How to Apply BI Tools to Policy Making Process}

On the way to sustainability, there is an argent need to integrate and apply behavioural insights in policy making process. According to (OECD, 2019), it requires gathering professionals and practitioners from behavioral science area as a part of the team whose task is designing public policies and developmental programs. That team must be qualified to apply behavior insights, behavioural economics, cognitive and social psychology, experimental design and statistics in the policy making process. Applying BI \& BE tools to achieve sustainability is an empirical effort and takes time to identify policy problems, develop strategies, design, set up and run experiments, as well as implement on a larger scale and deliver advice on behavioural strategies for public policy.

The case study of (The UK Behavioural Insights Team, 2014) proved and support our findings. UKBIT has developed many valuable principles to practitioners to integrate into policy design and implementation to help people stick to their plans (which in turn can help in directing behaviours toward more sustainable patterns of life). To make desired changes in society's members' behaviours, the following principles must be clear to policy makers:

- Make the targeted behaviour easy: The world is complicated enough and when individual is enforced to achieve multiple goals at once, even relatively small problems may become a motive for delaying acting. "Make the best choice, the easy choice", that is so called "Choice Architecture". 
- Default effect by cognitive avoidance: When individuals are automatically contributed to a join specific policy or target, all obstacles mut be removed. To do that, practitioners must use defaults as a short way to shift the individual's' behavior toward the targeted option.

- Framing and Priming: As information can be offered in different various ways, the way that information is presented can influence behavior dramatically which means that small variations in the messages and/or choices afforded to individuals can extremely change their perceptions and -in turn-affect their daily decisions. In addition, human behavior is influenced by unconscious cues that are experienced before a decision or behavioral prompt.

- Provide plans and feedback: In many cases, shifting daily human behavior toward desired practises needs repeating in a continuous pattern to be a part of individuals" habits or we can say "life culture" or "lifestyle". To maintain that, many methods could be used, such as highlighting specific information to increase the probabilities of responding to it in a desired way, along with affording continuing feedback to persons about their behavior to help them to evaluate and assess their own behavior and modify it if required. Moreover, the transparency of providing regular feedback helpe people stick to a long-term goal and stay on track.

- Implementation intentions: A good method to achieve long-term goals is dividing each complicated goal small executive goals to design an organized action plan which could be implemented easier (Gollwitzer \& Brandstätter, 1997; Gollwitzer, 1999).

- Create commitments (social expectations): Social norms consists of values, expectations, and practises of a society and offer guides to behavior either implicitly or explicitly. Hence, social norms are categorised into two categories: descriptive norms depending of what others really do, and injunctive norms related to what should be done regarding the available information about any phenomena.

- Manage "present bias": Theoretically, the "present bias" denotes that individuals have more tendency to provide higher weight to payoffs that are closer to the present time when considering trade-offs between two future moments. In the context of integrating behavioral insights, specifically psychological factors, and social norms in designing public policies, it is necessary to adopt the acceptable outcomes for developing more policy intervention given the expected costs and benefits potentially resulting from the intervention and then derive the number of participants needed to detect such an effect with an acceptable probability (O’Donoghue \& Rabin, 1999).

- Simplify messages and processes to reduce cognitive requirements: Simple massages and process have positive impacts of behavior through helping persons to work easier to control their actions and make more accurate decisions as a result of cognitive load.

- Design contextual cues to make the better choice automatic: Regarding that individuals usually react in an automatic manner in responding to their environmental considerations, related contextual cues can encourage specific behaviors and discourage others.

\subsection{Empirical Evidences and Case Studies}

Empirical evidence supports the efficiency of using the above-mentioned principles to change behaviors toward more sustainable patterns of actions. Countries' experiences proved that understanding human behavior and integrating behavior economics principle into policy designing help in achieving public policies' targets and increase the efficiency and outcons of those policies. (Texas Department of Transportation, n.d.; Texas Times, 2016; Pichert \& Katsikopoulos, 2008; and Orbell, Hodgkins, \& Sheeran, 1997). 


\subsection{How to Shift Behaviors Toward Sustainability}

Darnton (2008) offered practical application on "Designing policy interventions with behavioral insights" and develop one of the most popular models in UK, "The nine principles" model which suggests an iterative cyclical process in policy development and application. According to that model, the process of moving from step to step is iterative, meaning that insights from later steps might imply revision of the earlier assumptions and steps. The circle represents the idea of "learning by doing" where the interventions are being continuously refined because of ongoing monitoring and evaluation.

The framework of the "nine principles" model involves the following nine steps for policy makers to achieve desirable changes in individuals' behavior (Bonsall et al., 2009):

1) Recognizing the targeted community and the targeted behavior. If behavior is complicated, it should be divided into simple and small behaviors or components.

2) Identifying related behavioral models and selecting the most important factors affecting behavior.

3) Employing the main factors influencing behavior to develop the intervention policy.

4) Classifying effective intervention procedures that were effective in the former interventions in targeting definite factors.

5) Involvement of the targeted persons for the intervention in well understanding of their behavior and the main factors influencing that behavior from the target audience viewpoint.

6) Developing a model intervention and evaluate it against related policy contexts and evaluating methods.

7) Modelling the intervention and displaying the outcomes.

8) Evaluating effects and procedures against the purposes of the intervention policy in relation to the factors affecting behavior.

9) Concluding the main points explored to extend understanding of the intervention and the target behavior.

Future research must be continued to explore new mechanisms to achieve sustainability using BI tools. Moreover, the policy implications- discussed in this study and others- require further analyses to be applied on various developed and developing countries, specifically in designing the long-term policies as the empirical and applied studies in that area is very limited. Expanding and adaption of that valuable approach of shifting behaviours towards sustainability is critical to improve the accuracy and effectiveness of local and global sustainability targeting policies.

\section{Conclusion}

Most of the environmental crisis and unsustainable aspects in the world are caused by people. So, people are the solution. Achieving sustainability requires changes in human behavior and actions in relationship to the economic, social, and environmental SDGs. Individuals follow their own self-interest which lead to ineffective results usually ignore external costs and benefits of their activities on others. Behavioral economics can help policy makers to understand individuals' motivations toward specific behavior and the incentives that should be used to change behavior to more desirable directions, and steps of designing policies to achieve desirable outcomes. Traditional economic theories studied individual behavior regardless that social interactions influence individual choices, but humans are social species and human behavior is more complex. So, changing or modifying behavior is more than challenging. Policies that imply behavioral change need good understanding of how people behave in different circumstances and contexts. Applications of behavioral science can be used to 
strengthen existing public policies and programmes and improving their outcomes. In terms of achieving sustainability, behavioral insights and behavioral economics tools can help in improving the efficiency of environmental, social, and economic legislation and policy-based incentives, as well as increasing the influence of education and informational programmes to change the way individual choices affect the process of sustainability. This study concluded that behavior economics' tools are applicable to enhance sustainable development dimensions (environmental- economic and social dimension). The empirical evidence showed and proved the effectiveness of integrating behavioural insights and techniques in policy making designing and implementation and its positive impacts on policies' outcomes, specifically in the context of achieving sustainable development goals with more concentrating on goals $1,2,6,7,12$, and 13. Using deductive qualitative approach, and a comparative analysis, the study discussed many important mechanisms to help practitioners and policy makers in employing behavioural insights to shift the general behavior in the society toward sustainability.

Funding: This research received no external funding

Conflicts of Interest: The author declares no conflict of interest.

\section{References}

Allcott, H. (2011). Social Norms and Energy Conservation. Journal of Public Economics, 95(9-10), 1082-1095. https://doi.org/10.1016/j.jpubeco.2011.03.003

Banerjee, A. V., \& Sendhil, M. (2008). Limited Attention and Income Distribution. American Economic Review, 98(2), 489-493. https://doi.org/10.1257/aer.98.2.489

Beerbaum Dr., D., \& Puaschunder, J. M. (2018). A Behavioral Economics Approach to Digitalization. Proceedings of the $10^{\text {th }}$ International RAIS Conference on Social Sciences and Humanities.

Beerbaum Dr., D., \&Puaschunder, J. M. (2019). A Behavioral Economics Approach to Sustainability Reporting. https://doi.org/10.2139/ssrn.3381607

Brundtland, G. H. (1987). Our common future-Call for action. Environmental Conservation, 14(4), 291-294. https://doi.org/10.1017/S0376892900016805

Casini, M., Bastianoni, S., Gagliardi, F., Gigliotti, M., Riccaboni, A., \& Betti, G. (2019). Sustainable Development Goals Indicators: A Methodological Proposal for a Multidimensional Fuzzy Index in the Mediterranean Area. Sustainability, 11, 1. https://doi.org/10.3390/su11041198

Charness, G., \& Matthew, R. (2002). Understanding Social Preferences with Simple Tests. The Quarterly Journal of Economics, 117(3), 817-869. https://doi.org/10.1162/003355302760193904

Costa, F. (2012). Can Rationing Affect Long Run Behavior? Evidence from Brazil. Unpublished paper, EPGE Brazilian School of Economics and Finance, Latin America. https://dx.doi.org/10.2139/ssrn.2028684

Daniel, P., \& Konstantinos, V. K. (2008). Green defaults: Information presentation and pro-environmental behavior. Journal of Environmental Psychology, 28(1), 63-73. https://doi.org/10.1016/j.jenvp.2007.09.004

Darnton, A. (2011). Reference Report: An overview of behaviour change models and their uses, Oxford University Press.

Fawad, K. (2019). Behavior Economics is fast becoming relevant to develop sustainable Development Goals. South Asia Journal, 29. Retrieved from http://southasiajournal.net 
Gabaix, X., David, L., Guillermo, M., \& Stephen, W. (2006). Costly Information Acquisition: Experimental Analysis of a Boundedly Rational Model. American Economic Review, 96(4), 1043-1068. https://doi.org/10.1257/aer.96.4.1043

Geller, H., \& Attali, S. (2005). The experience with energy efficiency policies and programs in IEA countries. Retrieved from http://citeseerx.ist.psu.edu/viewdoc/download?doi=10.1.1.463.4039\&rep=rep1\&type=pdf

Gollwitzer, P. (1999). Implementation Intentions: Strong Effects of Simple Plans. American Psychologist, 54, 493-503. https://doi.org/10.1037/0003-066X.54.7.493

Gollwitzer, P. M., \& Brandstätter, V. (1997). Implementation intentions and effective goal pursuit. Journal of Personality and Social Psychology, 73(1), 186-199. https://doi.org/10.1037/0022-3514.73.1.186

GreeNudge. (2013). Potensialet for nudging i narks klimapolitikk (p. 11). GreeNudge, Oslo.

Habyarimana, J., ack, William, Heckle, \& Chide. (2011). Results of a randomized road safety intervention in Kenya. Journal of Public Economics, 95(11), 1438-1446. https://doi.org/10.1016/j.jpubeco.2011.06.008

Heukelom, F. (2014). Behavioral Economics: A History (p. 117). Nova York: Cambridge University Press. https://doi.org/10.1017/CBO9781139600224

Jensen, R. (2012). Do Labor Market Opportunities Affect Young Women's Work and Family Decisions? Experimental Evidence from India. Quarterly Journal of Economics, 127(2), 753-792. https://doi.org/10.1093/qje/qjs002

Kallbekken, S., \& Sælen, H. (2013). Nudging' Hotel Guests to Reduce Food Waste as a Win-Win Environmental Measure. Economics Letters, 119, 325-327. https://doi.org/10.1016/j.econlet.2013.03.019

Kenneth, G., \& Karen, P. (2014). Bridging the Energy Efficiency Gap: Policy In sights from Economic Theory and Empirical Evidence. Review of Environmental Economics and Policy, 8(1), 18-38. https://doi.org/10.1093/reep/ret021

Loewenstein, G., \& Lerner, J. S. (2003). The Role of Affect in Decision Making, In R. Davidson, H. Goldsmith, \& K. Scherer (Eds.), Handbook of Affective Science (pp. 619-642). Oxford, Oxford University Press.

Marianne, B., Esther, D., \& Sendhil, M. (2004). How Much Should We Trust Differences-In-Differences Estimates. The Quarterly Journal of Economics, 119, 249-75. https://doi.org/10.1162/003355304772839588

O' Donoghue, T., \& Matthew, R. (1999). Doing It Now or Later. American Economic Review, 89(1), 103-124. https://doi.org/10.1016/j.jenvp.2007.09.004

OECD. (2019). Tools and Ethics for Applied Behavioural Insights: The BASIC Toolkit. https://doi.org/10.1787/9ea76a8f-en

Orbell, S., Hodgkins, S., \& Sheeran, P. (1997). Implementation Intentions and the Theory of Planned Behavior. Personality and Social Psychology Bulletin, 23(9), 945-954. https://doi.org/10.1177/0146167297239004

Saugato, D., \& Sendhil, M. (2014). Behavioral Design; A New Approach to Development Policy. Review of Income and Wealth, 60(1), 1-29. https://doi.org/10.1111/roiw.12093

Sent, E. M. (2004). Behavioral Economics: How Psychology Made Its (Limited) Way Back into Economics. History of Political Economy, 36, 735-760. https://doi.org/10.1215/00182702-36-4-735

Sergey, S. R., Todd, D. C., ... Nancy, N. R. (2014). Cost-effective targeting of conservation investments to reduce the northern Gulf of Mexico hypoxic zone. PNAS, 111(52), 18530-18535. 
https://doi.org/10.1073/pnas.1405837111

Shohel, M. M. C., \& Howes, A. J. (2011). Models of Education for Sustainable Development and Nonformal Primary Education in Bangladesh. Journal of Education for Sustainable Development, 5(1), 129-139. https://doi.org/10.1177/097340821000500115

Stephen, P., Catherine, L. K., Simon, A. L., Stephen, R. C., ... Jane, L. (2019). Role of Economics in Analyzing the Environment and Sustainable Development. PNAS. 116(12), 5233-5238. https://doi.org/10.1073/pnas.1901616116

Stordalen, G. A., \& Steffen, K. (2014). Grønne nudge for trippel vinn Sustainable United Nations Development Program 2020, Sustainable Development Goals. Retrieved from https://www.undp.org/content/undp/en/home/sustainable-development-goals.html

Sunstein, C. (2014). Why Nudge? The Politics of Libertarian Paternalism (pp. 1-195).

The Intergovernmental Panel on Climate Change (IPPC). (2019). Retrieved from https://www.ipcc.ch/data/

United Nations Development Program (UNEP). (2020). Sustainable Development Goals. Retrieved from https://www.undp.org/content/undp/en/home/sustainable-development-goals.html

United Nations Environment Program (UNEP). (2017). Consuming Differently, Consuming Sustainably: Behavioral Insights for Policy Making. Retrieved from https://sustainabledevelopment.un.org/content/documents/2404Behavioral\%20Insights.pdf

\section{Copyrights}

Copyright for this article is retained by the author(s), with first publication rights granted to the journal.

This is an open-access article distributed under the terms and conditions of the Creative Commons Attribution license (http://creativecommons.org/licenses/by/4.0/). 